ISSN 2305-2678 (Print); ISSN 2305-5944 (Online)

DOI: http://dx.doi.org/10.4314/rj.v28i1.6

\title{
Comparative study of effects of table sugar, laboratory grade sucrose and mannitol on growth of banana plantlets under in vitro conditions.
}

Rukundo Placide, Ulinzwenimana Clément, Uwase Fraçoise and, Ahishakiye Védaste

E-mail: rukundoplacide@yahoo.fr, Tel: +25078612423/+27783930397

\begin{abstract}
$\underline{\text { Abstract }}$
A study was conducted to investigate effects of table sugar, laboratory grade sucrose and mannitol on growth of banana plantlets under in vitro conditions. Plantlets of banana of Injogo variety were grown on Murashige and Skoog (premixed) basal medium with vitamins $\left(4.4 \mathrm{~g} x l^{-1}\right)$ supplemented with $1 \mu M$ benzylaminopurine and $1 \mu M$ indole acetic acid. The experiment was executed in two phases. In the first phase, $30 \mathrm{~g} x$ $l^{-1}$ of laboratory grade sucrose, table sucrose and mannitol was used with no sugar as a control treatment. In the second phase of the experiment, the quantity of carbohydrates was reduced to $15 \mathrm{~g} x \mathrm{l}^{-1}$. Data on growth rate and fresh weigh gain was collected. After four weeks, plants grown on the culture medium with laboratory grade sucrose showed consistently higher growth rate and more gain in fresh weight (2.395 and $1.039 \mathrm{~g}$ respectively for 30 and $15 \mathrm{~g}$ of sugar per litre of culture medium) as compared to the other treatments $(1.397,0.110$ and $0.373 \mathrm{~g}$ for $30 \mathrm{~g}$ of sugar per litre of culture medium, and $0.767,0.355$ and $0.638 \mathrm{~g}$ for $15 \mathrm{~g}$ of sugar per litre of culture medium, respectively for the table sugar, mannitol and control). The plantlets grown on the culture medium with mannitol showed the lowest gain of fresh weight. This indicates that mannitol is a poor source on energy for banana plantlets. This study indicated a possibility of replacing the laboratory grade sucrose by the table sugar without significant loss in quality and growth so as to reduce the production cost of in vitro plantlets of banana.
\end{abstract}

Key words: Banana, tissue culture, sugars, table sugar, laboratory grade sucrose, mannitol.

\section{INTRODUCTION}

The growth of explants under in vitro conditions depends on nutritional and environmental factors which interact to produce a plantlet with similar characteristics to those grown in the field (ZRYD, 1988). The optimization of medium composition is an important approach to hasten the micropropagation 
process and improve the quality of regenerated plantlets through culture of cells, tissues and organs (LIU et al., 2006). These cultures require a carbohydrate supply in order to satisfy the energy demand (DE PAIVA NETO and OTONI, 2003). Different sugars such as sucrose, glucose, maltose, fructose and sorbitol were proven to have effects on the growth of plantlets under in vitro conditions. However, sucrose is the most commonly used carbohydrate in the plant tissue and cell cultures and the majority of the in vitro studies have concluded that sucrose supports near optimal rates of growth (SMITH, 1995; CUENCA and VIEITEZ, 2000; FUENTES et al., 2000; MELLO et al., 2001). Some of the important features of sucrose that make it more preferable are its wide spread use as transport molecule in plant system, high solubility in water, electrical neutrality, and its apparent lack of inhibitory effect on the majority of biochemical processes (SMITH, 1995). Consequently, sucrose is among media components that are routinely used in plant tissue culture. However, the unavailability and prohibitive cost of laboratory grade sucrose are among major constraints of tissue culture laboratories found in developing countries.

The laboratory of ISAR Rubona uses the table sugar in tissue culture of banana to reduce the production cost. However, there is not quantitative data proving the efficiency of this sugar. The objective of this investigation was to compare the efficacy of table sugar, laboratory grade sucrose and mannitol on the growth of banana plantlets under in vitro conditions.

\section{MATERIALS AND METHODS}

The study was carried out at the banana tissue culture laboratory of Rwanda Agriculture Board (RAB) located at Rubona Station, in South Province of Rwanda. In vitro plantlets of banana variety Injogo (highland triploid banana with a genome AAA) was used for the experiment. Plantlets at sixth subculture stage were grown for one month to develop a root system on the basic liquid rooting culture medium formulated with product acquired from Duchefa, the Netherlands. The culture medium was prepared as follows: $4.4 \mathrm{~g} \mathrm{x} 1^{-1}$ Murashige and Skoog (MS) salts with vitamins, $0.09 \mathrm{M}$ sucrose, $1 \mu \mathrm{M}$ benzyl amino purine (BAP), and $1 \mu \mathrm{M}$ indole acetic acid (IAA). The $\mathrm{pH}$ of the culture medium was adjusted at 5.6. After one month, the plantlets were used for two experiments. Each experiment consists of three treatments of different carbohydrates and control. The culture media used in these experiments were prepared with $4.4 \mathrm{~g} \mathrm{x}$ $1^{-1}$ MS salts with vitamins, $1 \mu \mathrm{M}$ BAP and $1 \mu \mathrm{M}$ IAA. This culture medium was supplemented with three types of carbohydrates. In the first experiment, $30 \mathrm{~g}$ of 
laboratory grade sucrose, table sugar and mannitol per litre of culture medium were three treatments. The control of this experiment was the culture medium without sugar. For the second experiment, the parameters were the same as in the first experiment except the quantity of sugars was reduced at $15 \mathrm{~g}$ per litre of culture medium. Fresh weights of explants at the initiation stage were determined with analytical balance. The conditions in the growth room were 16 hours of light, 8 hours of darkness and $25-26^{\circ} \mathrm{C}$. After every week, 10 plantlets grown on each culture medium were selected randomly to determine the gain of fresh weight as a difference between the initial fresh weight and final fresh weight. Data were analyzed using GenStat $14^{\text {th }}$ Edition.

\section{RESULTS AND DISCUSSION}

Three treatments of culture media prepared with laboratory grade sucrose, table sucrose and mannitol, and a control without sugar were used in the study to identify their effects on a growth of banana plantlets under in vitro conditions. The results of this study showed a growth variation for plantlets grown on the culture media with different sugars (Fig. 1). The plantlets grown on the culture medium with laboratory grade sucrose and table sugar showed a high growth compared to the growth of plantlets grown on the culture medium with mannitol and the culture medium without sugar (Fig.1 a, b). It was also observed a growth difference between plantlets grown on the culture medium with mannitol and culture medium without sugar (Fig. 1a). The plantlets grown on the culture medium with laboratory grade sucrose were more vigorous than the plantlets grown on the culture media with table sugar (Fig. 1b). These plants presented a high gain of fresh weight compared to the plants grown on the culture media with other carbohydrates and culture medium without sugar (Fig. 2 and 3).
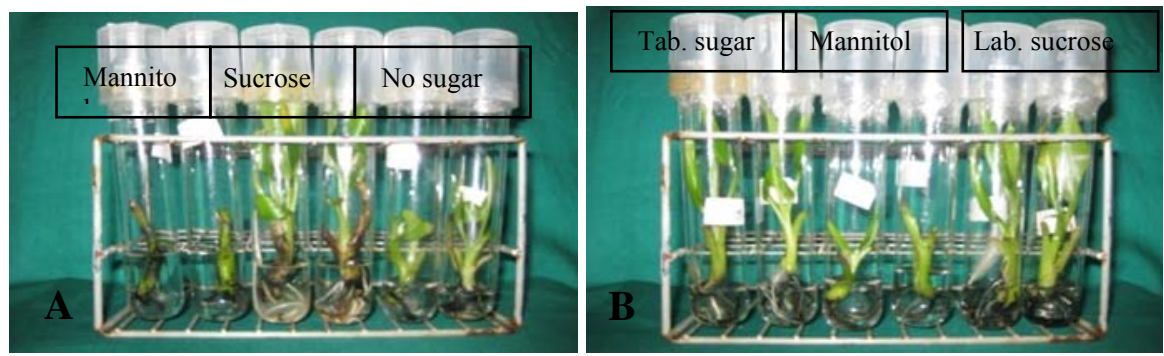

Figure 1: Effects of table sugar (tab. sugar), laboratory grade sucrose (lab. sucrose) and mannitol on growth of banana plantlets under in vitro conditions. 
The plantlets grown on the culture medium with mannitol revealed the lowest gain of fresh weight. The variance analysis and mean separation (Tukey HSD test $)$ of fresh weight data showed a statistically significant difference $(\mathrm{P}<0.05)$ between plantlets grown on the culture medium with laboratory grade sucrose and the culture medium with table sugar, when the quantity of sugar was $30 \mathrm{~g} \mathrm{x}$ $1^{-1}$. However, there was no significant difference $(\mathrm{P}<0.05)$ when the quantity of sugar was $15 \mathrm{~g} \mathrm{x}^{-1}$ (Fig. 2 and 3). A relationship between the quantity of sucrose and the gain of fresh weight was also observed. The gain of fresh weight was very high on plantlets grown on culture medium with $30 \mathrm{~g} \mathrm{x}^{-1}$ of laboratory sucrose (Tab. 1 and 2). This gain of fresh weight was reduced to the half for plantlets grown on culture media with $15 \mathrm{~g} \mathrm{x}$ - $^{-1}$ of culture medium (Fig. 2 and 3, Tab. 1 and 2).

Table 1: Changes in gain of fresh weight for banana plantlets grown in different sugars at concentration of $30 \mathrm{~g} \mathrm{x}^{-1}$ of culture medium (Values are average of ten plantlets measured every week).

\begin{tabular}{lcccc}
\hline & \multicolumn{4}{c}{ Week } \\
\cline { 2 - 5 } Culture medium & $1^{\text {st }}$ & $2^{\text {nd }}$ & $3^{\text {rd }}$ & $4^{\text {th }}$ \\
\hline Laboratory sucrose & 0.799 & 1.198 & 1.996 & 2.395 \\
Control & 0.198 & 0.123 & 0.258 & 0.373 \\
Table sucrose & 0.378 & 0.651 & 1.124 & 1.397 \\
Mannitol & 0.008 & 0.032 & 0.071 & 0.110 \\
\hline
\end{tabular}

Table 1: Changes in gain of fresh weight for banana plantlets grown in different sugars at concentration of $15 \mathrm{~g} \mathrm{x} \mathrm{l}^{-1}$ of culture medium (Values are average of ten plantlets measured every week).

\begin{tabular}{lcccc}
\hline & \multicolumn{4}{c}{ Week } \\
\cline { 2 - 5 } Culture medium & $1^{\text {st }}$ & $2^{\text {nd }}$ & $3^{\text {rd }}$ & $4^{\text {th }}$ \\
\hline Laboratory sucrose & 0.417 & 0.551 & 0.734 & 1.017 \\
Control & 0.262 & 0.397 & 0.511 & 0.636 \\
Table sucrose & 0.369 & 0.433 & 0.550 & 0.767 \\
Mannitol & 0.158 & 0.231 & 0.282 & 0.355 \\
\hline
\end{tabular}




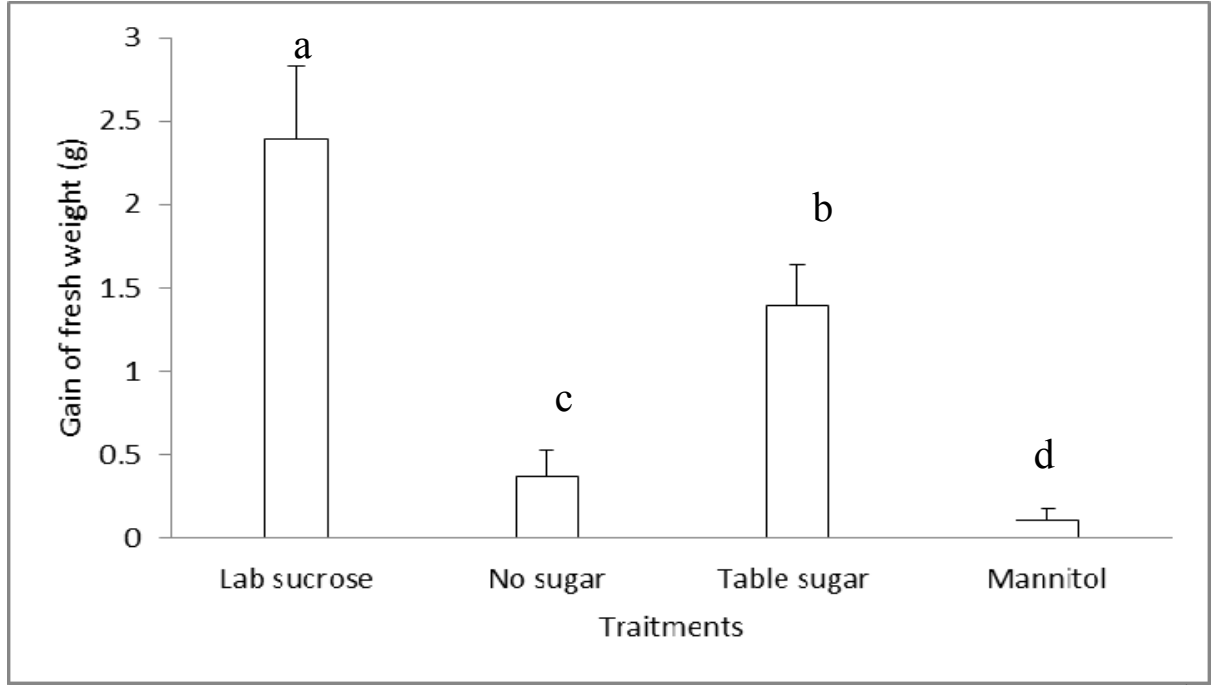

Figure 2: Mean of gain of fresh weight for banana plantlets grown on culture media $\left(30 \mathrm{~g} \mathrm{x}^{-1}\right)$ with laboratory grade sucrose, table sugar and mannitol, under in vitro condition.

Blocks marked with the same letter are not significantly different $(\mathrm{P}<0.05)$.

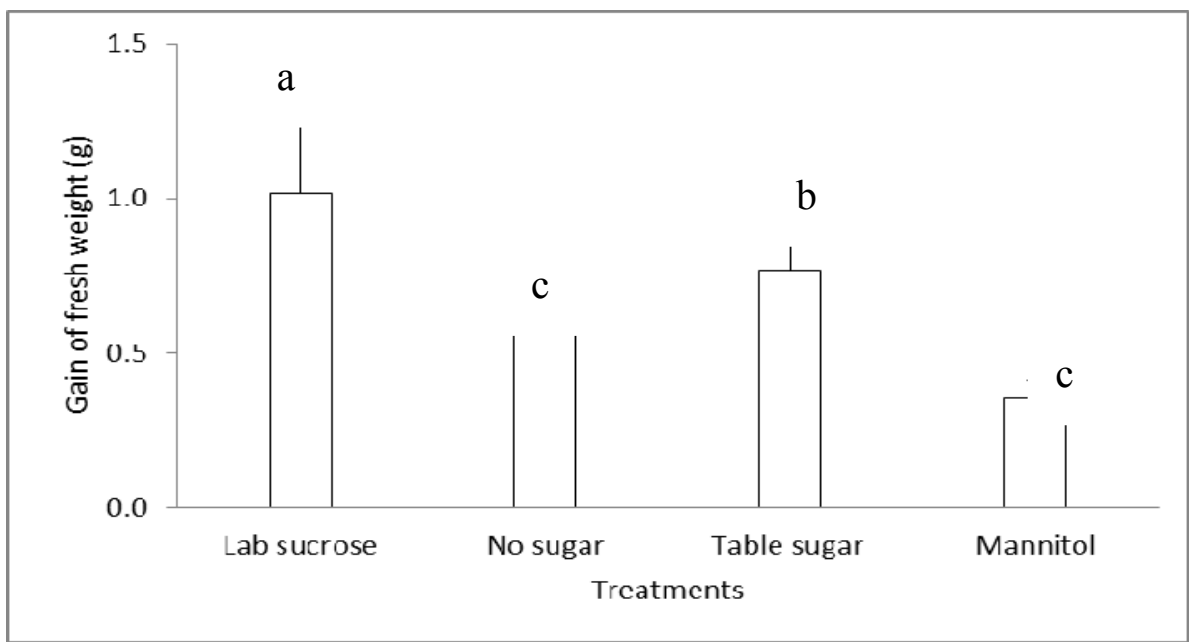

Figure 3: Mean of gain of fresh weight for banana plantlets grown on culture media $\left(15 \mathrm{~g} \mathrm{x} \mathrm{^{-1 } )}\right.$ with laboratory grade sucrose, table sugar and mannitol, under in vitro condition. Blocks marked with the same letter are not significantly different $(\mathrm{p}<0.05)$. 
The same statistical analysis showed that there was a significant difference $(p<0.05)$ in fresh weight gain between plants grown on the culture media with mannitol and the culture media without sugar, when $30 \mathrm{~g}$ of mannitol was used. Nevertheless, no significant difference $(p<0.05)$ was observed when the

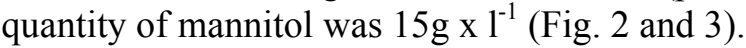

Studies comparing the effects of different sugars on the growth of in vitro explants have showed that sucrose has the highest positive effects. This finding resulted to its wide use in tissue culture as a carbon source (PETERSEN et al., 1999; WANG et al., 1999; FUENTES et al., 2000; MELLO et al., 2001; LIU et al., 2006). The positive effects of sucrose on growth of explants under in vitro condition is linked with its high solubility in water, its electrical neutrality and its lack of inhibitory effect on the majority of biochemical processes (SMITH, 1995). The results of this study correlate with these previous findings where sucrose showed the highest growth rate and gain of fresh weight compared to other treatments. It was also noted that the use of laboratory grade sucrose resulted in the highest growth rate and gain of fresh weight than table sugar. In experiments, it is known that the use of reagents of high quality is among factors that increase the quality of results. Then, this difference between the laboratory grade sucrose and the table sugar could be associated with the quality of these sugars. According to the indication of container, the purity of laboratory grade sucrose was $85 \%$. This purity indicates that the quality of laboratory grade sucrose could be higher that the quality of the table sugar.

It was revealed that the ability to metabolize different types of carbohydrates differs within the plant kingdom and the response of shoot cultures to different carbohydrate treatments appears to be genotype dependent (CUENCA and VIEITEZ, 2000). It was also suggested that the negative effects of some sugars on the plant growth is caused by their inefficiency metabolization by cells of these crops. This inability to utilise any sugar by in vitro plantlets could be due either to its reduced uptake or to the absence or insufficient degrading enzyme activity in these plant species (JAIN et al., 1997). These could be the main causes of a low growth rate and gain of fresh weight of plantlets grown on the culture medium with mannitol.

The dissolution of culture medium components, especially macronutrients and carbon source causeS a considerable decrease of the medium osmotic potential $\left(\Psi_{\mathrm{s}}\right)$ (DE PAIVA NETO and OTONI, 2003). It is known that the water potential $\left(\Psi_{\mathrm{w}}\right)$ is a sum of the individual components denoted as effects of 
solutes $\left(\Psi_{\mathrm{s}}\right)$ and pressure $\left(\Psi_{\mathrm{p}}\right)$ respectively on the free energy of water (TAIZ and ZEIGER, 2006). The increase of concentration of solutes in a solution results to more negative $\Psi_{\mathrm{s}}$. Consequently, the decrease of solution $\Psi_{\mathrm{s}}$ will affect the $\Psi_{\mathrm{w}}$ of the culture media and water availability for a plantlet. Then, this water limitation affects the physiology and growth of plantlets. This could explain the differences in fresh weight gain that was significant between plantlets grown on the culture medium without sugar and culture medium with mannitol, when $30 \mathrm{~g}$ of mannitol was used, and non-significant difference that was observed when the quantity of mannitol was $15 \mathrm{~g}$ per litre of culture medium (Fig. 2 and 3). It is possible that $30 \mathrm{~g}$ of mannitol per litre of culture medium imposes a considerable osmotic potential which causes negative effects on the water availability in the culture medium. Therefore, plantlets grown on this culture medium suffer from shortage of water.

\section{CONCLUSIONS}

The laboratory grade sucrose showed the highest effect to support the growth of banana plantlets under in vitro condition at a level of $30 \mathrm{~g} \mathrm{x}^{-1}$. However, reducing sugar levels to $15 \mathrm{~g} \mathrm{x} \mathrm{l}^{-1}$ of culture medium results in less weight gain and growth. Table sugar was able to support growth of the banana plantlets to the same level as laboratory sucrose. Therefore, to reduce the production cost of in vitro plantlets the table sugar can be used. But, it is necessary to explore the weaning rate of plantlets from this two treatments before the final recommandation because it was observe that plantlets grown on the culture medium with table sucrose are not strong compared to counterparts of the laboratory grade sucrose. The results of this study also revealed that mannitol is a poor source of energy for banana plantlets under in vitro conditions. There is a need to investigate the causes of this property so as to understand whether banana plantlet can not absorb or metabolize mannitol. This knowledge could assist to decide if mannitol could be used as a neutral osmotic inducer in screening of drought tolerance banana varieties or used in the in vitro conservation of banana germplasm.

\section{Acknowledgements}

The banana in vitro laboratory of $R A B$ is thanked for excellent technical assistance and the Rwanda Ministry of Agriculture is thanked for financial support. 


\section{REFERENCES}

1. CUENCA, B. \& VIEITEZ, A., 2000. Influence of carbon source on shoot multiplication and adventitious bud regeneration in in vitro beech cultures. Plant growth regulation, 32 (1), pp.1-12.

2. DE PAIVA NETO, V. B. \& OTONI, W. C., 2003. Carbon sources and their osmotic potential in plant tissue culture: Does it matter? Scientia Horticulturae, 97 (3-4), pp.193-202.

3. FUENTES, S. R. L., CALheiRos, M. B. P., MANETTI-FILHO, J. \& VIEIRA, L. G. E., 2000. The effects of silver nitrate and different carbohydrate sources on somatic embryogenesis in Coffea canephora. Plant cell, tissue and organ culture, 60 (1), pp.5-13.

4. JAIN, R., DAVEY, M., COCKING, E. \& WU, R., 1997. Carbohydrate and osmotic requirements for high-frequency plant regeneration from protoplastderived colonies of indica and japonica rice varieties. Journal of experimental botany, 48 (3), pp.751.

5. LIU, T. H. A., LIN, J. J. \& WU, R. Y., 2006. The effects of using trehalose as a carbon source on the proliferation of Phalaenopsis and Doritaenopsis protocorm-like-bodies. Plant cell, tissue and organ culture, 86 (1), pp.125129.

6. MELlO, M. O., DIAS, C. T. S., AMARAL, A. F. C. \& MELO, M., 2001. Growth of Bauhinia forficata Link, Curcuma zedoaria Roscoe and Phaseolus vulgaris L. cell suspension cultures with carbon sources. Scientia Agricola, 58 (3), pp.481-485.

7. PETERSEN, K. K., HANSEN, J. \& KROGSTRUP, P., 1999. Significance of different carbon sources and sterilization methods on callus induction and plant regeneration of Miscanthus x ogiformis HondaGiganteus'. Plant cell, tissue and organ culture, 58 (3), pp.189-197.

8. SMITH, C., 1995. Carbohydrate chemistry. LEA, PJ; LEEGOOD, RC Plant biochemistry and molecular biology. Chichester: John Wiley \& Sons, pp.73111.

9. TAIZ, L. \& ZEIGER, E., 2006. Stress physiology. Plant Physiology, Taiz, L. and E. Zeiger (Eds.). Sinauer Associates, Inc., Sunderland, MA., pp.671-681.

10. WANG, H. L., LEE, P. D., LIU, L. F. \& SU, J. C., 1999. Effect of sorbitol induced osmotic stress on the changes of carbohydrate and free amino acid pools in sweet potato cell suspension cultures. Botanical Bulletin of Academia Sinica, 40 (7), pp.219-225.

11. ZRYD, J. P., 1988. Cultures de cellules, tissus et organes végétaux. Fondements théoriques et utilisations pratiques. Lausanne: Presses polytechniques romandes. 